\title{
Recognition, Redistribution, and Liberty
}

\author{
Anne D. Collins \& Jamus Jerome Lim*
}

March 28, 2008

\begin{abstract}
This paper examines the relationship between redistribution, recognition, and liberty. In particular, it critiques the arguments made by authors such as "Fraser \& Honneth" (2003) about how redistribution is a simple subset of recognition, and how recognition is both necessary and sufficient for redistribution to occur. It argues, instead, that it is the relatively weak assumption of (minimal) individual liberty that allows recognition (and hence redistribution) to exist, and that while recognition is necessary, it is insufficient for redistribution, if liberty is to be respected. Finally, it shows that this approach is, ultimately, a more robust and sustainable strategy to understanding the problems posed by discrimination and social inequality.
\end{abstract}

JEL Classification: H23, P16

Keywords: Identity politics, redistributive politics, liberalism

*Centre College and The World Bank, respectively. Emails: 'collins@centre.edu, and lj]lim@world̄ank.orgi Heartfelt thanks go out to Bob Martin, Bob Meister, and $\overline{\text { Heather }}$ Morton for their incisive comments on the manuscript, and to seminar participants at the University of California, Santa Cruz and Centre College, for their thoughtful comments and lively discussions, which helped shape my understanding and approach toward this subject. We are alone responsible for any blatant misreadings, flagrant assumptions, and fatal errors. Financial support from the Institute of Humane Studies paid for some of the beer consumed over the course of this project. 
The socialist society would have to forbid capitalist acts between consenting adults... no distributional-patterned principle of justice can be continuously realized without continuous interference with people's lives.

Anarchy, State, and Utopia, p. 163 (Robert Nozick)

\section{Introduction}

Redistribution and recognition are two ideas that have long been a preoccupation of two very different, but deeply influential, schools of political theory and philosophy. The former-which finds expression in philosophers of social justice

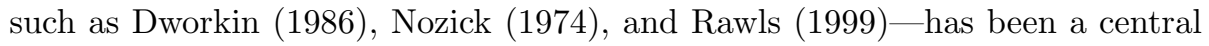
concern of class-based politics, while the latter-which has been premised on Hegelian philosophy and the various derivatives of the seminar led by Kojève (Kojève 1980) - has provided the intellectual underpinnings for understanding the politics of identity. Despite the importance of each of these fundamental ideas, however, the relationship between them has, unfortunately, remained undertheorized.

A clearer understanding of this relationship is of both theoretical and practical value. When treated as separate theoretical constructs, the perspectives appear to be fundamentally independent: Recognition is a microfoundational concern which, as a philosophy, presages a deeper understanding of the realized structure of observed society; it is, by design, an ex ante approach. In contrast, redistribution is a functional concept, which implicitly accepts what may be a defective system and seeks to effect corrective action based on an ex post philosophy of an ideal. This dichotomy, however, masks the importance of how one necessarily impacts the other, and how a complete theory of natural justice needs to recognize this interdependence.

The issues raised by these ideas also find currency in the practical policymaking debate. The framework of recognition-versus-redistribution has often been cast as the basis for two types of social movements: Traditional, interest-

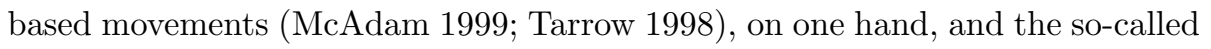
"new social movements" centered on various conceptions of culture and identity (Pichardo $19 \overline{9}$ ), on the other. What were hitherto academic disputes over the linkages between class and identity politics have since found immediacy due to the eruption of ethnic, religious, and sectarian violence - especially among poor, disaffected, unemployed youths - in France, Rwanda, Indonesia, Darfur,

\footnotetext{
${ }^{1}$ Following Kant, these authors consider respect as the morally relevant kernel of recognition, from which redistribution can then follow. Another approach to the problem, therefore, would treat the distinction between the two schools as one where the focus is on respect, instead of recognition. Our concern here is with relationship between redistribution and recognition, which we view as a broader concept, and for which respect is a subset. As such, we lay aside this difference for the purposes of this paper. The notion of respect, however, is an integral component of our definition of liberty, as will become clear in what follows.
} 
and elsewhere. One is left to ponder whether such events would have occured if policy aimed at enhancing recognition somehow addressed the dislocations felt by these protagonists, or if redistributive policy could have lessened the economic hardship faced by them.

The two major theorists that have examined the linkages between redistribu-

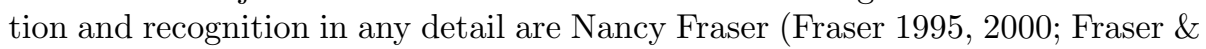
'Honneth' 2003) and Axel Honneth (Fraser \& Honneth"2003; Honnethi 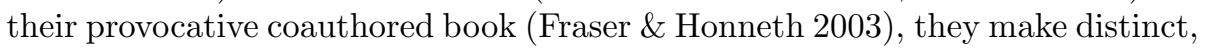 but related, arguments for understanding the relationship between redistribution and recognition. The former seeks to develop a "two-dimensional conception of justice that encompasses both types of claims without reducing either type to the other," while the latter instead proposes a "normative monism of recognition... that seeks to subsume the problematic of redistribution within it." ("Fraser \& Honneth 2003 p. 3). The common ground between these disparate approaches lies in their rejection of the "economistic view that would reduce recognition to a mere epiphenomenon of distribution" (Fraser \& Honnethin $200 \overline{3}$ p. 2).

We dispute this claim that rational decisionmaking necessarily reduces the role of recognition to a secondary outcome, with no potential impact on redistributive choices. Indeed, as will be argued, a view that embraces individual choice allows us to introduce the notion of liberalism in a very appealing way - a way that provides an alternative conceptualization of the problematic, and one that allows us to go beyond the linkages between redistribution and recognition that have been raised by the authors ${ }^{2}$ !

The objective of this paper is to contribute to the understanding of the relationship between redistribution and recognition by introducing the fundamental

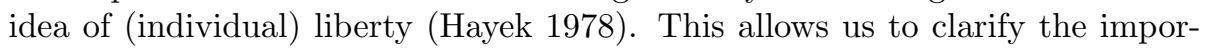
tance of liberty in allowing for recognition to occur in the first place, and to decouple the presumption that the politics of recognition and redistribution must imply each other. This immediately raises the question of whether redistribution is the appropriate response to recognition, ex post, or whether, sometimes, recognition may be enough. By not compounding the two issues, we further our understanding of, and potential for addressing, the real political-economic problems of racial and cultural integration, gender discrimination, and chronic poverty.

Our framework is founded on a condition of minimal liberalism. That is, if we wish to respect an individual's right to be decisive over just one pair of alternatives in any given environment, then redistribution must necessarily be treated as an independent issue from recognition. This methodologically individualist approach may, perhaps, be unappealing due to its noninterventionist

\footnotetext{
${ }^{2}$ It should also be noted at the outset that our approach is, in the main, positive and not normative; as such, our definitions of redistribution and recognition - and any implications from our findings - are not limited to simply those that may be justified, but to all possible treatments of these concepts (assuming agreement with the premises). Nonetheless, we are aware that our formalization does sacrifice some of the conceptual richness that are embodied in a more discursive approach.
} 
prescription. Nonetheless, it lends itself to a more robust and, ultimately, sustainable approach to the problem of social inequality.

It is important at the outset to make a clear distinction between liberalism and both capitalism and democracy. The specific application of minimal liberalism that we utilize is essentially focused on the individual and his or her freedom over decisionmaking processes. It is not tied to any specific systemic features, such as capitalism (economic) or democracy (political). At its heart, our argument is therefore independent of specific institutional superstructures. In addition - and to the extent that an emphasis on minimal liberalism may be viewed as an inalienable right - our argument is also value-free (although the case for this may be more difficult to make).

The difficulties associated with the difficulties of reconciling individual decisionmaking with collective choice, and its implications on liberalism, is not a new one. However, most previous studies were built on an explicit social choice framework, which takes the primacy of recognition as a given. This, we feel, relegates to the background the important issue of the existence of recognition to begin with. Moreover, the issues explored generally had a different substantive focus: These have ranged from Pareto optimality (Sen democracy ('Riker"1982), to the existence of a social welfare function ('Arrow' $(\overline{1} \overline{7} \overline{0})$. The focus of this paper, in contrast, is on how liberalism influences the interactions of recognition and redistribution.

The paper is structured as follows. The following section describes the approaches to redistribution and recognition as advanced by critical theory. This is followed by a description of the formal framework, and a presentation of the

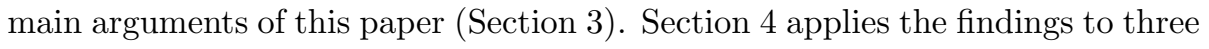
cases, before a final section concludes.

\section{The Critical Approach to Redistribution and Recognition}

The modern theory of recognition and its relationship to redistribution finds its most systematic treatment within the broad framework of critical theory. The three most distinct models have been those articulated by Nancy Fraser (i $\overline{\text { Fraser }}$ !

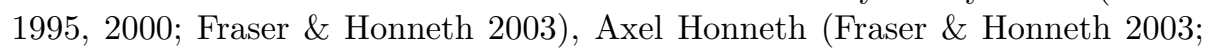
Honnethi'1996), and Charles Taylor ('Taylor 1992,12001 ).

Taylor's approach stresses the importance of recognition in the formation of identity, as well as the role that respect plays in affording that recognition. Such respect, of course, can neither be coerced or bought: "[T] he judgement of value is to register something independent of our own wills and desires, [and] it cannot be dictated by a principle of ethics" (Taylor 1992 p. 69). As a result, recognition is built on an underlying conflict: The tension between a "politics of difference," where individuals possess a unique identity, set against a "politics of dignity," which emphasizes the universality of dignity among all citizens.

While this model raises some interesting questions concerning the assump- 
tions of (Kantian) liberalism - in particular how difference-blind politics may "negate... identity by forcing people into a homogeneous mold that is untrue to them" (Taylor"1992 p. 43) - the concept is focused on recognition per se as a means of distributive justice. In some ways, Taylor almost regards recognition as equivalent to a means of redistribution, insofar as the acquisition of recognition automatically grants equality of rights, and that is all that matters. Since Taylor's approach does not draw clear distinctions between the two concepts of redistribution and recognition, we will focus on Fraser's and Honneth's models in what follows.

The work of Fraser and Honneth, in contrast, revolves around trying to understand the recognition-redistribution relationship, with each playing a distinctive role. The authors' specified goal is one of "reconstruct[ing] the conceptual underpinnings of critical theory" (Fraser $\bar{E}$ Honneth' debate that they engage in provides a coherent framework that places recognition on equal theoretical footing with redistribution. This makes their work immediately cogent to our concerns, since most accounts of redistribution have tended to underprivilege recognition. The basis for their critique - the lens that they use to frame their theory - follows the tradition of the Frankfurt School, which is premised on the perceived failures of capitalism.

Fraser's strategy for addressing the relationship builds on a moral conception of justice that is fully two-dimensional, in that it believes in the separate coherence of both recognition and distribution. This translates, in the social sphere, as a "perspectival dualism" that melds economy with culture; in the political sphere, this dualism is seen as a form of democratic justice that emphasizes affirmation (to correct inequitable outcomes) and transformation (of the underlying social structure). Misrecognition is treated not as "depreciation and deformation of group identity, but social subordination... requir[ing] a politics of recognition" to redress the injustice ('Fraserin $200 \overline{0}$ p. 113).

The relationship between redistribution and recognition, therefore, is to Fraser one that is irreducible; the two are tied by necessity and sufficiency. This is made explicit in her arguments about social welfare. On one hand, redistributive policies "cannot succeed unless it is joined with struggles for cultural change aimed at revaluing. ... associations that code it. In short, no redistribution without recognition" (Fraser $\bar{E}$ Honneth' $200 \overline{3}$, p. 65 , italics in original). On the other, "recognition reforms cannot succeed unless they are joined with strug-

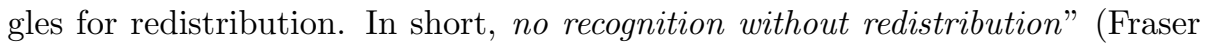
"' $\overline{\mathrm{H}}$ onneth" $20 \overline{0} 3$, p. 66 , italics in original). The message is clear: We need a theory that breaks the false dichotomy of class/status, economy/culture, and maldistribution/misrecognition - a dichotomy introduced and sustained by the capitalist system. We need a system that integrates redistribution with recognition, and vice versa.

Fraser is not alone in an approach that conflates the linkages between re-

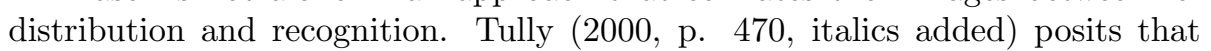
any "struggle to alter the identity-related norms under which citizens are led to recognize themselves and others will have effects in the distribution or redistribution of the relations of power among them." Moreover, while he suggests that 
distribution necessarily alters the prevailing norms associated with recognition, the causal channels and prerequisite mechanisms that allow such alterations are not fully articulated. Similarly, 'Young $(20 \overline{0} \overline{2}$, p. 105) argues that "problems of lack of recognition. . . are usually tied to questions of control over resources.... A politics of recognition, that is, usually is part of or a means to... an end to structural inequalities."

The sharp distinctions that Fraser makes sits uncomfortably with Honneth. While he rejects any theory of natural justice that is not accompanied by redistribution, he regards the social injuries faced by individuals as ultimately one of a failure of recognition - a view that he asserts is based on a phenomenological approach to social experiences of injustices. This connotes a "normative monism" of mutual recognition that, when properly understood, differentiates into the three spheres of love (in intimate relationships), the equality principle (in legal relations), and achievement principle (in the social hierarchy). Moreover, recognition occurs at several levels in reality, and society is simply a fragile structure of these graduated recognitions.

The relationship is now one where redistribution is subordinate to recognition, and may be subsumed by it ("Fraser \& Honneth" 2003 p. 152):

All struggles for recognition. . progress through a playing out of the moral dialectic of the universal and the particular: One can always appeal for a particular relative difference by applying a general principle of mutual recognition, which normatively compels an expansion of the existing relations of recognition.

He refuses to "theoretically isolate purely economic or systemic factors from cultural elements" ("Fraser \& Honneth 2003 p. 156), since cultural values play a constitutive role in economic struggles; the centrality of this understanding of culture is starkly captured by his claim that "what motivates individuals or social groups to call the prevailing social order into question and to engage in practical resistance is the moral conviction that. . . the recognition principles considered legitimate are incorrectly or inadequately applied" (i'Fraser \& Honneth' 2003 , p. 157, italics in original). Like Fraser, Honneth is not the only one that propounds this view: (Yar 2001 p. 297-298) is even more succint: "[T]he struggle for recognition underpins claims over economic redistribution... economic goods are in-and-of-themselves mediated forms of recognition."

Are these two approaches the only way to understand the redistributionrecognition relationship? One is immediately struck by how the respective authors' commitment to rooting the problematic in the structure of capitalism may potentially hide some more subtle distinctions between the two. We are not alone in this criticism: "Feldmani ( $200 \overline{2}$ p. 411) notes, in a different context, how "state power becomes a 'blind spot' in the redistribution/recognition framework." His view is that the real injustice develops through civil society, rather than the state, and in his essay he expands Fraser's theory of maldistribution and misrecognition to incorporate specifically political forms of injustice, or political marginalization due to the state. Our present paper, in contrast, 
takes the diametrically opposite view and makes its case based on the freedom of the individual.

\section{Minimal Liberty and its Effects on Recogni- tion and Redistribution}

Having laid out the main approaches used for understanding the problematic of redistribution and recognition, this section lays out our view of recognition and redistribution that not only treats the two issues as separate, but goes further to claim that confounding them can lead to detrimental consequences for our understanding of contemporary problems - as well as our proposed solutions.

The nature of recognition finds its antecedent in the Hegelian conception of the Other ( $\overline{\mathrm{H}} \overline{\mathrm{ege}} \mathrm{l}, \overline{1} \overline{0} \overline{\mathrm{T}})$, and, more precisely, in the varied interpretations, extensions, and modifications of the Hegelian Other by the Kojèvean reading of Hegel - authors such as Sartre, Lévinas, Bataille, Foucault, and Lacan. The work of these authors provide the microfoundations for proponents of identity politics, through post-Hegelian refinements of recognition, such as "the Look" (Sartre), the "Mirror Phase" (Lacan), "the Face" (Lévinas). The subtle distinctions between these alternative conceptualizations are, for our present purposes, tangential. We therefore abstract from a fuller examination of these distinctions and instead focus on the general ideal of recognition: That is, a relationship between a given subject and object that sees the other as equal, distinct, but mutually codependent for their existence - either literally or, more commonly, figuratively obtained from others. We are now in a position to operationalize this definition of recognition.

Definition 1 (Recognition). Let the recognition of a specific group $j$ by another $i$ be a purposive event represented by $\rho_{i j}=\rho_{j i} \neq\{\varnothing\}$. Then, a group $j$ is said to be recognized by $i$ (and vice versa) when $j \in \rho^{i} \subset \mathfrak{R}$, where $\mathfrak{R}$ is the set of all possible recognitions for groups in society.

Although primarily theoretical in nature, recognition has a strong practical component. However such recognition comes about, it is the basis for understanding how different groups may be perceived to exist in society. Thus, in the absence of recognition, it is not possible to entertain differences in the entire host of socio-economic indicators - whether this exists in income, wealth, education, or self-realization - since such differences need to be defined to begin with. In other words, any corrective action in terms of redistribution must surely be premised on a proper recognition that such groups even exist. This, of course, is precisely the argument that Honneth seeks to make: That in order

\footnotetext{
${ }^{3} \mathrm{~A}$ related, but distinct, concept is that of identity, which is the manner in which individuals form their self-image. Identity can be a source of utility (A kerlof $\bar{E}$ Kranton can in turn shape both individual behavior as well as the manner by which such individuals 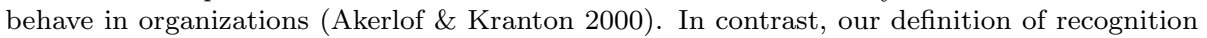 is premised on the formation of a given image of
} 
for us to fully effect the program of redistribution - in accordance to any given experienced social injustice - recognition becomes a prerequisite, and hence can be profitably subsumed into the broader redistributive paradigm. In fact, as will become clear in our main proposition below, this precondition is indeed a necessary condition for redistribution to occur.

Redistribution, or more precisely, economic redistribution, can be traced

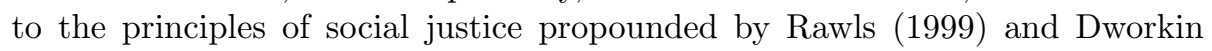
$(\overline{1} \overline{8} \overline{6} \overline{6})$. Such theories of distributive justice may be classified according to either a time-dependent (diachronic) or subjunctive (synchronic) baseline; indeed, redistribution according to special — as opposed to general — interests can easily be accommodated, if one wished. Moreover, whether redistribution is used for affirmative or transformative purposes is secondary. Redistribution is effected whenever there is a real transfer of resources from one entity to another,

Definition 2 (Redistribution). Let a real transfer from a specific group $i$ to another $j$ be an action represented by $\tau_{i j}>0$. Then, a group $j$ is said to be the recipient of a redistribution from $i$ when $j \in \tau^{i} \subset \mathfrak{T}$, where $\mathfrak{T}$ is the set of all possible redistributive schemes in the universe of this society.

Note that this definition of redistribution need not be coercive: In fact, redistribution that occurs as a result of natural shocks to the economy could give rise to scenarios where, even when starting from a position of ex ante equality, we arrive at a distribution where inequality grows without bound (iucasi $\overline{1} \overline{9} \overline{2})$. We establish, in what follows, that even in noncoercive circumstances, it is possible to find situations where redistribution is possible.

In any modern society, we generally wish to espouse some minimal form of individual liberty. Most societies hold certain rights as inalienable, regardless of implications for social efficiency; a relevant document in this regard is the U.N. Universal Declaration of Human Rights. The strict adherence to all the articles notwithstanding (such as full religious freedom, universal suffrage, and freedom of peaceful assembly), the right to some degree of autonomy in leisure, life, and security appear to be generally upheld. We seek to capture this ideal in the definition of minimal liberalism, below.

Definition 3 (Minimal liberalism). Following Sen (1970), minimal liberalism is said to hold when, in a society with at least two individuals, there is at least one pair of alternatives over which an individual $i$ is decisive. That is, for any pair of alternatives $\left\{\tau^{\prime}, \tau^{\prime \prime}\right\}$ or $\left\{\rho^{\prime}, \rho^{\prime \prime}\right\}$, if $\tau^{\prime} \succ_{i} \tau^{\prime \prime}$, then $\tau^{\prime} \succ \tau^{\prime \prime}$ (and, respectively, if $\rho^{\prime} \succ_{i} \rho^{\prime \prime}$, then $\rho^{\prime} \succ \rho^{\prime \prime}$ ), where $\succ_{i}$ and $\succ$ are preference relations for the individual and society, respectively. A society $\sigma$ that exhibits this property exists in the set $\mathfrak{L}$.

Such minimal liberalism is best explicated by example. Suppose that a member of an ethnic minority chooses not to recognize the credibility of a white supremacist group. Then a society that allows minimal liberalism should permit

\footnotetext{
${ }^{4}$ For simplicity, we assume that society begins from a state of Pareto optimality. Our definition of redistribution, therefore, does not include efficiency-enhancing exchanges.
} 
this person to do so, even if everyone else in society chooses otherwise. Similarly, given other recognitions in society, if the wealthy parents of a gay son afflicted with HIV choose to privately provide for his needs, then society must allow such an arrangement, even if the national health insurance system does not uphold the gay son's rights to health claims from the system. Note as well that our conception of freedom does not imply democracy (Tully 2000$)$, nor is it implied $b y$ it (Taylor" 2001 ). In that sense, the minimal liberalism defined here is more akin to the classical liberal definition of freedom (inayek

Given these definitions, we are now in a position to state our first proposition, which establishes minimal liberty as a precondition for recognition.

Proposition 1. Minimal individual liberty is required for recognition.

Proof. See appendix.

We make two brief remarks about this proposition.

First, with minimal liberalism, the statement by Honneth that he "reinterprets the socialist ideal of redistribution as a subvariety of the struggle for recognition" ("Fraser \& Honneth" 2003 p. 3) becomes more difficult to support, at least in terms of socialism, traditionally defined. Of course, how much freedom an individual may enjoy under a socialist regime is open to interpretation, but the point is that framing both redistribution and recognition in terms of socialist discourse does not lend additional credence or weight to the argument in any way. If anything, we would contend that such language distracts from a fuller, value-free understanding of the relationship between the two concepts.

Second, it is important to emphasize the primacy of minimal liberty as a prerequisite for recognition. This argument has, in a limited sense, actually been anticipated by ${ }^{\prime} \bar{R} \bar{l}$ ey: $(2 \overline{0} 0 \overline{2})$ in the context of cultural pluralism. In that work, he defends a limited cultural pluralism that insists on "common considerations of truth, morality, and aesthetic taste" (Riley that work, however, we have left both the specific criteria for liberty as well as forms of recognition largely unspecified. Moreover, we do not resort to a critique of specific shortcomings of the aesthetic, antiuniversalist, or moralist argument. While we agree with Riley that such defenses of unlimited pluralism are inadequate, our proposition above is even stronger: If one wishes to even accommodate any form of pluralism, minimal individual liberty is the necessary starting point.

Proposition 2. Given (minimal) individual liberty, recognition of a group is a necessary, but insufficient, condition for redistribution to that group.

Proof. See appendix.

This is the central proposition of this paper, and hence deserves some comment.

First, note that the proposition is one of necessity and not sufficiency. As such, it is entirely congruous with Honneth's notion of redistribution as a form 
of recognition. In fact, while the formal statement $\tau \Rightarrow \rho$ may not fully constitute the intricacies of Honneth's argument, it represents the main thrust of his case. However, both Fraser and Honneth take as given the sufficiency aspect of the proposition, which is, demonstrably, false. The natural implication of this result is that, conditional on minimal liberty, we can decouple any discussion of redistribution with that of recognition, once we have established the necessity of recognition. That is, given that recognition has been attained, we can no longer take for granted that redistribution is implied. If we believe in redistribution in and of itself, this needs to be meaningfully pursued, not assumed as an outcome.

Second, given the fairly weak conditions used to establish minimal liberalism, it seems uncontroversial to allow for such individual liberty to exist. That is, given all other possible redistributions in society, there should be at least one redistribution for which, if an individual prefers not to effect, then society should respect that choice. For example, if a poor individual prefers not to give a donation to a wealthy individual, that option should be available to him or her. Similarly, it does not seem unreasonable for a Jewish holocaust survivor to possess the minimal right to insist that he does not have to provide monetary support to a neo-Nazi organization. Note that this claim is far weaker (in terms of its moral premises) than arguments that have been made by, for example,

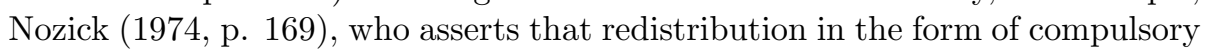
taxation is "morally on par with forced labor." Here, such broad claims are not necessary for the proof of the proposition to hold.

Third, this condition probably finds an intellectual analogue in Sen's theorem on the impossibility of a Paretian liberal, although its focus in on an entirely different issue. For Sen, liberalism cannot coexist with Pareto optimality in social choice, In essence, Sen's theorem suggests that a strict adherence to the Pareto principle is necessarily inconsistent with individual liberty. Here, in contrast, we make no assumptions concerning the optimality of the social choice function. Instead, we abstract from this thorny problem in order to draw conclusions concerning the consistency of a chain of causality from recognition to redistribution, given (minimal) individual liberty.

Extending the idea of Proposition '22! from individual to society is straightforward.

Corollary 1. In a liberal society, recognition is a necessary, but insufficient, condition for redistribution.

Proof. See appendix.

The claim that all redistributive actions must lie within society's recognitions $(\tau \subseteq \rho)$ is intuitive. Essentially, the primacy of recognition should be underscored; there is absolutely no incongruence with a statement that claims that "redistribution [is] a subvariety of the struggle for recognition." However, since this is not a strict subset - there may be recognitions that exist outside of the redistributive set - this suggests that in some cases, at least, redistribution

${ }^{5}$ The full theorem (ISen 1970 principle, but also unrestricted domain, which is secondary in our discussion here. 
must necessarily be coercive, in the sense that it violates the preferences of a given group not to engage in such redistribution. This is the case even if it should choose to recognize the group that is the beneficiary of its transfer.

This idea that redistribution does not follow from recognition has also found some limited experimental validation in the laboratory. Using caste as a basis for

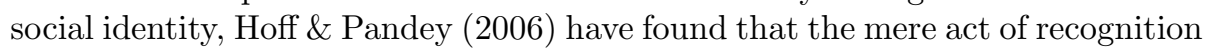
can lead to differential performance by subjects in simple cognitive tasks. In their experiments, the revelation of caste information - which effectively enabled recognition since caste would otherwise be unobservable - led to a significant caste gap, which did not exist in the absence of such revelation. The endogenous emergence of such stereotype-based expectations implies that inequalities may be durable, even after the removal of de jure discriminatory institutions. While it is tempting to infer that this implies the need for forced redistribution, such coercive action introduces its own set of problems, as we discuss below.

While both Proposition ' $2 \bar{L}$ ' and Corollary 'î̀' are purely positive statements, they have strong normative implications. $\overline{\mathrm{By}}$ insisting on the sufficiency of recognition for redistribution, both Fraser and Honneth subscribe to a belief in the "distinctive dialectic of immanence and transcendence," which accommodates redistribution and recognition simultaneously ("Fraser $\&$ Honnethi, p. 202). Thus, Honneth's ultimate rejection of the "individualist achievement 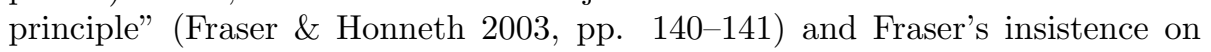 "perspectival dualism" (Fraser \& Honneth" $200 \overline{3}$, p. 63) both display their (implicit) assumptions about the desirability of redistribution. Since recognition no longer implies redistribution, whether coercive or noncoercive, we can now examine the relative merits (and demerits) with respect to redistribution, free from the shackles that tie one to the other. This can be rephrased as a corollary.

Corollary 2. A society that seeks to respect minimal liberalism can choose whether or not to redistribute to groups that it recognizes. In other words, the question of redistribution is indeterminate in a liberal society.

The dilemma posed by this result is that we do not have a clear prediction regarding redistributive outcomes in a liberal society. This need not, however, be viewed as a shortcoming in our analysis; after all, the empirical evidence suggests that even in highly liberal societies, such as the United States, we observe a substantial amount of private charity! ${ }^{\prime} !$ ! This allows us to break away explanations which claim that America's small welfare state is due to "American exceptionalism." Indeed, it has been argued that the absence of European-style welfare systems in the United States may possibly be attributed to the latter's belief that equality of opportunity (in terms of social mobility) far exceeds

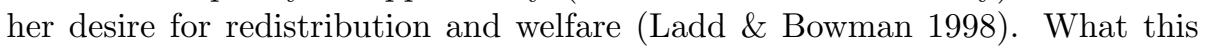
suggests, therefore, is that there is simply no a priori reason to accuse a society

\footnotetext{
${ }^{6}$ Bergstrom, Blume \& Varian $(\overline{19} \overline{8} \bar{b})$ make the formal case that government provision of a public good may, under certain conditions, lead to the "crowding out" of private provision. Viewed in this light, voluntary redistribution can be viewed as a substitute for the absence of government-enforced redistribution financed by taxation.
} 
that carries liberal ideals of indifference toward the problems of inequality and poverty.

The foregoing discussion naturally begs the question: If, in a liberal society, we divorce recognition from redistribution, what are we left with to form a theory of redistribution? By what basis can we make claims for or against redistribution?

One direction, implied by our analysis, is that redistributive outcomes should rest solely in the domain of an individual. The case for this goes beyond methodological individualism, however. Given the time-inconsistency problems that will inevitably be introduced in any dynamic redistribution problem, maintaining incentive compatibility over time becomes more than a trivial matter. Here, the work on wealth redistribution based on a dynamic political-economic equi-

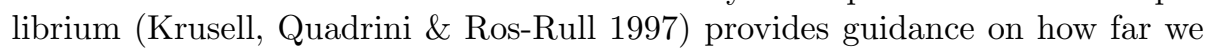
can carry the static results derived in models of general-interest politics (Meltzer

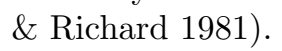

Although it may seem that liberalism completely removes any incentive toward redistribution, this need not be the case. If we are willing to assume that individuals face uncertainty over their future welfare - perhaps due to idiosyncratic shocks to their income stream - then a system of redistribution can be dynamically sustained, as long as a system of transfers exists such that individuals faced with a negative shock receive positive transfers. Our claim is then simply a variation of the argument concerning infinitely-repeated Prisoner's Dilemma problems - one that accounts for uncertainty over future outcomes'

More formally, let $W_{i, t}\left(\tau_{i j, t}\right)$ be the welfare of an individual $i$ at time $t$. We do not impose any functional form restriction on this representation of welfare, although we do assume that preferences at any single point in time are stable, and that welfare is decreasing (increasing) in transfers to (received from) others $\left(\frac{\partial W}{\partial \tau_{i j}} \leq 0\right.$ and $\frac{\partial W}{\partial \tau_{j i}} \geq 0$, respectively). Moreover, the welfare of individuals are allowed to differ. Notice as well that welfare is a function of transfers $\tau_{i j, t}$ from $i$ to $j$ at time $t$. Let the probability of a one-time idiosyncratic negative shock to income $y$ be given by $\pi$.

Definition 4 (Redistribution rule). Let $\tau^{*} \in \mathfrak{T}$ be a rule where $y_{i}<\bar{y}_{i} \Rightarrow$ $\tau_{j i, t}>0$, where $\bar{y}$ is average income.

This is simply a mechanical rule that effects a transfer to an individual if he or she experiences the negative income shock that brings it below average income. We can now claim the following proposition.

Proposition 3. Voluntary redistribution is sustainable in a liberal society in the presence of uncertainty when following the redistribution rule $\tau^{*}$, as long as transfers received are sufficiently large relative to transfers given.

Proof. See appendix.

\footnotetext{
${ }^{7}$ Binmore $(2004)$ provides a nice, nontechnical discussion of the use of game-theoretic approaches in resolving problems in the social contract.
} 
This proposition provides, in a very simple model, a potential resolution to the problem of indeterminacy in redistribution in a liberal society. Intuitively, allowing for uncertainty over future income introduces an insurance motive that can support voluntary redistribution. Moreover, since the exact nature of this shock is inessential to the proof, the proposition also allows for a variety of interpretations regarding the idiosyncratic shock. One such interpretation is that of social security against unexpected negative economic outcomes, such as the loss of a job, although this would require a fairly loose understanding of the term "voluntary" redistribution. An alternative interpretation is that of social mobility: If an individual believes that he will, in the future, experience a downward move in social stratus, then he will be more willing to contribute toward a transfer today.

The proof hinges on the condition that the increase in welfare from transfers received are relatively large, as compared to the welfare loss from the initial transfer given $\left(W_{i, t}\left(\tau_{j i, t}>0\right) \gg W_{i, t}\left(\tau_{i j, t}>0\right)\right)$. This would be the case if either loss aversion is sufficiently high (so that for a fixed transfer $\tau_{i j}$, $\left.\left.\frac{\partial W}{\partial \tau_{i j}}\right|_{\tau_{i j}>0} \ll \frac{\partial W}{\partial \tau_{i j}}\right|_{\tau_{i j}<0}$ ), or if the absolute amount of the transfer received is much greater than the transfer given $\left(\tau_{j i} \gg \tau_{i j}\right)$. The latter possibility, in particular, is possible if drawdowns on the common pool occur relatively infrequently, or if the pool is allowed to grow over time through some interest-yielding

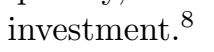

Proposition '3"'it can also serve as the basis for a partial explanation for charitable or philanthropic behavior. This would be based on true intersubjective recognition, as opposed to recognition by a government that effects redistributive outcomes. In this regard, to the extent that mutual recognition is a desirable goal for society, voluntary redistribution through the risk sharing motive may pave the way for improved social relations between members. This additional benefit may be seen as a positive externality that arises from purely self-motivated behavior. After all, redistributive equality sans recognition of the other as an equal may be of questionable moral value.

One interesting discussion that this analysis opens up is how discrimination, whether by race, culture, or gender, should be addressed after recognition. Arguably, African-Americans in the American South were recognized, even in the presence of discriminatory practices such as Jim Crow; recall that recognition need not imply either social or economic equality. If redistribution naturally followed from recognition, then any grievances must have somehow been paid previously, whether in tangible form or in the intangible. Arguments made in favor of ex post redistribution to "right past wrongs" need to contend with why the present generation should be forced to pay for the "sins of the fathers." This is especially so since, by Proposition' possible, from a theoretical point of view.

Furthermore, it is also unclear whether redistribution is the appropriate re-

\footnotetext{
${ }^{8}$ We have not explicitly modeled this constraint as we feel that it falls outside of the scope of this paper. However, we conjecture that for a given return $r$, the condition $r>\pi \delta_{i}$ is likely to be sufficient to ensure that an equilibrium exists even with drawdowns.
} 
sponse to ex post recognition. The existing models of multicultural integration adopted in Europe - ranging from the inclusive approach favored by Spain, to the multicultural tolerance approach employed in the Netherlands, to the economic meritocracy approach adopted by Britain, to universalist culture of the French - have all met with failures of various degrees in recent times ${ }^{\prime} \bar{l} ! \mid$ In all of these countries, save for Britain, there was direct economic redistribution to Muslim minorities, albeit in varying degrees. Still, the Madrid and London bombings, murder of Theo van Gogh, and French riots all attest to the difficulty of reducing the policy response to merely a redistributive one. While we do not propose to resolve this difficult issue here, we conjecture that a fuller justification for natural justice needs to take the dynamic issues discussed above more seriously, especially with respect to how true recognition in the long run would need to be accompanied by minimal liberalism.

Another alternative to the purely liberal approach involves a comparison of actual (realized) outcomes with that of Bergsonian social welfare functions that have been chosen by a central planner. This form of synchronic redistribution, of course, necessitates recourse to moral philosophy. In this case, a Benthamite (utilitarian) or Rawlsian social welfare function are both equally tenable. Equally, a Nash social welfare function (Kaneko \& Nakamurai $\overline{1} \overline{7} \overline{9}$ ), which satisfies a host of desirable properties, could be chosen. The problem with this approach, of course, is that such redistributive schemes may suffer from the enforcement and incentive-compatibility problems outlined above. Whether they are feasible as a practical matter, therefore, is an empirical question, and is dependent as much on the political-institutional structure of society as it is on the specific solution concept.

While the conditions described in Proposition'is̄'do presume the preexistence of recognition, this need not be the case. It is possible to envision of scenarios where recognition can arise endogenously in response to, say, a desire for tax revenues. To examine this more formally, we continue with the framework introduced above, but now let the probability of a one-time idiosyncratic positive shock to income $y$ be given by $\mu$.

Definition 5 (Taxation rule). Let $\tau^{\dagger} \in \mathfrak{T}$ be a rule where $y_{i}>\bar{y}_{i} \Rightarrow \tau_{i j, t}>0$, where $\bar{y}$ is average income.

This mechanical rule effects a transfer from an individual if he or she experiences a positive income shock that brings it above average income. The following proposition then follows.

Proposition 4. Voluntary recognition is sustainable in an authoritarian society in the presence of uncertainty when following the taxation rule $\tau^{\dagger}$.

Proof. See appendix.

Thus, even in a completely illiberal society, recognition can exist if a group is sufficiently likely to receive a positive income shock that would bring it above

\footnotetext{
${ }^{9} \mathrm{~A}$ nice discussion of the failures of the different approaches to Muslim integration in Europe is contained in i $\overline{\text { Forsythi }}(\overline{2} \overline{0} \overline{0} \overline{5})$.
} 
the mean of society. As long as uncertainty exists over whether a given group is going to receive this positive shock, the temptation to recognize this group, ex ante, become irresistible. Hence, given a rule that only allows taxation if groups are recognized beforehand - a rule perhaps enshrined in a constitutioneven a dictator will be willing to recognize groups that it does not favor. The historical record suggests that issues related to taxation could have eventually led to the expansion of the franchise and political transitions in Europe during the nineteenth century (Acemoglu \& Robinson"i2000, '2001).

\section{An Application to Three Unfortunate Events}

The civil unrest in France erupted on October 27, 2005, sparked off by the accidental death of two teenagers, Zyed Benna and Bouna Traoré, in a workingclass banlieue in eastern Paris. While the event was initially confined to Paris, the unrest eventually spread to most urban areas, as well as some rural areas, in the country. The most visual image of the rioting were thousands of burning cars; by the time things returned to some degree of normalcy around November 17 , nearly 2,900 rioters, mostly urban youth of North African origin, had been arrested.

The riots were a reminder that liberté, égalité, fraternité remains an ideal that is not always realized or experienced by a disaffected subset of society. The originating event involved the electrocution of the teenagers at a power substation as they were fleeing a police pursuit. The flight, in turn, was prompted by the desire to avoid the lengthy questioning and detention that youths in the housing projects face on a fairly routine basis, allegedly as a result of discrimination. The riots were further fuelled by the controversial comments of Interior Minister Nicolas Sarkozy, who called the youth "racaille" - an inflammatory term best approximated by the English words "rabble" or "scum."

The events in France were a vivid reminder of how the absence of recognition beyond class structures can lead to real economic, political, and social costs. While individual liberty is one of the hallmarks of the French republic, such liberty neither guarantees nor assures that recognition must follow. In this case recognition was withheld, albeit implicitly, inducing a backlash that has led to a questioning of the true level of integration of immigrants in France as well as greater Europe. While, on this occasion, the youths were also economically disadvantaged, the central feature of the episode was a failure in the politics of recognition, not redistribution.

In contrast, the Rwandan genocide - involving the mass extermination of Tutsis and moderate Hutus in a 100-day period between April 6 and mid-July 1994 - could probably be traced to roots that offered recognition with selective redistribution. Under early Belgian colonial rule, the ethnic Tutsi minority was granted preferential status, using physical characteristics such as height and facial structure as a guide. Thus, what would have been largely artificial distinctions between two tribes that had lived in peace for centuries were now demarcated and used as a basis for economic redistribution. 
The initial bias toward the Tutsis was exacerbated by the reversal in Belgian support for the Tutsis in the period just before independence, when Brussels perceived the increasingly pro-independence sentiment among the Tutsi elite. By the time Rwanda achieved her independence in the July 1962, the first mass killings of Tutsis by Hutus had already occurred. The genocide of 1994, catalyzed by the assassination of (Hutu) President Juvénal Habyarimana, was only the most visible culmination of a long string of inter-ethnic conflicts.

The result of such a scheme of recognition with selective redistribution was, arguably, only possible in what was largely an unfree society. Colonial Rwanda was an artificial society that could neither sustain nor support voluntary redistribution; conditions were, if anything, detrimental to the development of a socio-economic structure that would be conducive for uncoerced redistributive justice. The active redistribution, in this case, was a source of conflict in and of itself.

The islands of Maluku are an idyllic chain of islands located on the eastern front of the Indonesian archipalego. Known as the Spice Islands of the Dutch East Indies, the islands are populated by ethnic Malays and Melanesians of Christian and Muslim belief. In the period from January 1999 through February 2002, however, Maluku also saw some of the worst sectarian violence ever experienced in East and Southeast Asia; this left thousands dead and many more injured as a result.

Maluku serves as a case of a situation where recognition occurred, but little, or no, redistribution was forthcoming. The ethnic Chinese, who were often Christian, dominated commerce in Maluku. Although the first signs of violence were not between Christians and Muslims but between rival Muslim gang members, confrontations quickly escalated, displaying a sectarian nature. Clashes between security forces - themselves either Christian or Muslim - led to the rise of the militias such as the Islamist Laskar Jihad. The absence of redistribution was exacerbated by the Asian financial crisis of 1997/98, which hit ordinary workers hard and left a vast army of unemployed, discontented individuals.

\section{Conclusion}

This paper has sought to clarify the linkages between recognition and redistribution, and how these are impacted by claims for individual liberty. To that end, we have critiqued the claims made by authors such as iFraser $\&$ Honnethi (2003) concerning how redistribution is a subset of recognition, and how recognition is a sufficient justification for redistribution. With a relatively mild condition of minimal liberalism, we have demonstrated that, first, liberty required for the realization of recognition; and second, recognition is a necessary, but not sufficient, condition for redistribution. The corollary to the latter is that liberal societies have complete flexibility in their choice of programs of redistribution. With the presence of uncertainty about future income, however, noncoercive redistribution can be shown to be possible and sustainable, and such uncertainty may also allow recognition to arise endogenously. 
While our findings represent an initial effort at clarifying the redistributionrecognition relationship, we believe that future research needs to take the issue of liberalism more seriously. We believe that existing efforts to capture the idea of freedom, such as that of 'Tullyi ( $(2000)$, have taken on too narrow an agenda, by restricting this discussion to democratic freedom. Moreover, given the wellestablished tension between individual freedom and a reasonable representation of social choice (Riker" $\overline{1} \overline{8} \overline{2}$ ), the introduction of recognition may serve as a useful tool for overturning some of the impossibility results that pervade the literature. This, in and of itself, is a major research project, and one that may be a promising avenue for future work.

Another area that may merit exploration stems from a shortcoming of the present paper. While we have characterized a host of negative results, we have not attempted to provide strong positive findings. We have done so to preserve the generality of our arguments, but introducing additional axioms may help generate sufficiency conditions that narrow down the conditions whereby redistribution and recognition may actually imply each other. Without being too presumptuous, we conjecture that a more restrictive institutional framework may potentially be helpful in this endeavor.

\section{References}

Acemoglu, K. Daron \& James A. Robinson (2000). "Why Did the West Extend the Franchise? Democracy, Inequality, and Growth in Historical Perspective". Quarterly Journal of Economics 115(4) (November): 1167-1199

Acemoglu, K. Daron \& James A. Robinson (2001). "A Theory of Political Transitions". American Economic Review 91(4) (September): 838-863

Akerlof, George A. \& Rachel E. Kranton (2000). "Economics and Identity". Quarterly Journal of Economics 115(3) (August): 715-753

Arrow, Kenneth J. (1970). Social Choice and Individual Values. Cowles Foundation Monographs. New Haven, CT: Yale University Press, 2nd edition

Bergstrom, Theodore C., Lawrence Blume \& Hal R. Varian (1986). "On the Private Provision of Public Goods". Journal of Public Economics 29(1) (February): 25-49

Binmore, Ken (2004). "Reciprocity and the Social Contract". Politics, Philosophy 85 Economics 3(1) (February): 5-35

Dworkin, Ronald (1986). Law's Empire. Cambridge, MA: Harvard University Press

Feldman, Leonard C. (2002). "Redistribution, Recognition, and the State: The Irreducibly Political Dimension of Injustice". Political Theory 30(3) (June): 410-440

Forsyth, James (2005). "Group Think". The New Republic (November 16)

Fraser, Nancy (1995). "From Redistribution to Recognition? Dilemmas of Justice in a 'Postsocialist' Age". New Left Review 1(212) (July-August): 68-93

Fraser, Nancy (2000). "Rethinking Recognition". New Left Review 3 (May-June): 107-120

Fraser, Nancy \& Axel Honneth (2003). Redistribution or Recognition? A PoliticalPhilosophical Exchange. New York, NY: Verso 
Hayek, Friedrich A. (1978). The Constitution of Liberty. Chicago, IL: University of Chicago Press

Hegel, Georg Wilhelm Friedrich (1807). Phänomenologie des Geistes. Oxford, England: Oxford University Press, new edition edition. Reissued in 1977

Hoff, Karla \& Priyanka Pandey (2006). "Discrimination, Social Identity, and Durable Inequalities". American Economic Review 96(2) (May): 206-211

Honneth, Axel (1996). The Struggle for Recognition: The Moral Grammar of Social Conflicts. Cambridge, MA: MIT Press

Kaneko, Mamoru \& Kenjiro Nakamura (1979). "The Nash Social Welfare Function". Econometrica 47(2) (March): 423-436

Kojève, Alexandre (1980). Introduction to the Reading of Hegel. Itaca, NY: Cornell University Press

Krusell, Per, Vincenzo Quadrini \& José-Vctor Ros-Rull (1997). "Politico-Economic Equilibrium and Economic Growth". Journal of Economic Dynamics and Control 21(1) (January): $243-272$

Ladd, Everett Carll \& Karlyn H. Bowman (1998). Attitudes toward Economic Inequality. Washington, DC: AEI Press

Lucas, Robert E., Jr (1992). "On Efficiency and Distribution". Economic Journal 102(411) (March): 233-247

McAdam, Doug (1999). Political Process and the Development of Black Insurgency, 19301970. Chicago, IL: University of Chicago Press, second edition

Meltzer, Allan H. \& Scott F. Richard (1981). "A Rational Theory of the Size of Government". The Journal of Political Economy 89(5) (October): 914-927

Nozick, Robert (1974). Anarchy, State, and Utopia. New York, NY: Basic Books

Pichardo, Nelson A. (1997). "New Social Movements: A Critical Review". Annual Review of Sociology 23 (August): 411-30

Rawls, John (1999). A Theory of Justice. Cambridge, MA: Belknap Press, revised edition

Riker, William H. (1982). Liberalism Against Populism: A Confrontation Between the Theory of Democracy and the Theory of Social Choice. New York, NY: W.H. Freeman

Riley, Jonathan (2002). "Defending Cultural Pluralism Within Liberal Limits". Political Theory 30(1) (February): 68-96

Sen, Amartya K. (1970). "The Impossibility of a Paretian Liberal". Journal of Political Economy 78(1) (Jan-Feb): 152-157

Tarrow, Sidney (1998). Power in Movement: Social Movements and Contentious Politics. Cambridge Studies in Comparative Politics. Cambridge, England: Cambridge University Press, second edition

Taylor, Charles M. (1992). "The Politics of Recognition". In Amy Guttman (editor), Multiculturalism: Examining the Politics of Recognition, pp. 25-73. Princeton, NJ: Princeton University Press

Taylor, Charles M. (2001). A Tension in Modern Democracy. Princeton, NJ: Princeton University Press 
Tully, James (2000). "Struggles over Recognition and Distribution". Constellations 7(4) (December): 469-482

Yar, Majid (2001). "Beyond Nancy Fraser's 'Perspectival Dualism"'. Economy and Society 30(3) (August): 288-303

Young, Iris Marion (2002). "Social Difference as a Political Resource". In Rosemary Foot, S. Neil MacFarlane \& Michael Mastanduno (editors), Inclusion and Democracy, pp. 81-121. Oxford, England: Oxford University Press

\section{Appendix}

\section{A.1 Proofs}

Proof of Proposition, ${ }_{1}^{1}$ Let all groups that are recognized in a given society exist in the set $\rho \subseteq \overline{\mathfrak{R}}$, and further assume that $\rho$ is closed and complete. This society is liberal, so $\sigma \in \mathfrak{L}$. We wish to demonstrate that minimal liberalism is necessary for recognition, $\rho \subset \mathfrak{R} \Rightarrow \sigma \in \mathfrak{L}$. We show this by contradiction. Suppose that there is no minimal liberalism, such that $\sigma \notin \mathfrak{L}$. Then there exists an individual $d$ (a dictator) for whom if $\rho \succ_{d} \rho^{\prime}$, then $\rho \succ \rho^{\prime}$, and who recognizes only $j$, so $\rho=\{j\}$. Let there also be an individual $i \neq d$ in society that recognizes $j^{\prime}$, and so $j^{\prime} \in \rho^{i} \subset \rho$. Then, $j, j^{\prime} \in \rho$. But $\rho=\{j\}$, which is a contradiction.

Proof of Proposition $1 \mathbf{2}_{\mathrm{s}}^{\mathrm{L}}$ Let the recognitions in society be $\rho \in \mathfrak{R}$, and the redistributions be $\tau \in \mathfrak{T}$, with both $\rho$ and $\tau$ closed and complete. To prove necessity, note that, without loss of generality, any redistributive action $\tau_{i j}$ from a group $i$ to another group $j$ requires that $j$ exist in the recognition set of society $\rho$ : That is, $\forall \tau_{i j}, i \neq j:\left\{\tau_{i j} \geq 0 \Rightarrow j \in \rho\right\}$, otherwise $\tau_{i j}$ would not be defined. We demonstrate the failure of sufficiency by contradiction. Let $j^{\prime} \neq j$ be a group that is recognized by $i$. Hence, $j^{\prime} \in \rho$. Suppose that $\rho_{i j^{\prime}} \Rightarrow \tau_{i j^{\prime}}$. Then, in every state of the world, $\exists \tau_{i j^{\prime}}$ such that $\tau_{i j^{\prime}}>0 \forall \tau \in \mathfrak{T}, \rho \in \mathfrak{R}$. However, with minimal liberty, $\exists \tau_{i j^{\prime}} \in \tau$ where $\tau_{i j^{\prime}}=0$, since individuals are always decisive in at least one choice, and in that particular case can choose not to effect a redistribution. Hence, we have a contradiction, which concludes the proof.

Proof of Corollary $1 \overline{1}_{\mathrm{s}}$ Without loss of generality, any redistributive action $\tau_{i j}$ from a group $i$ to another group $j$ requires that $j$ exist in the transfer set $\tau^{i}$ : That is, $\forall \tau_{i j}, i \neq j:\left\{\tau_{i j} \geq 0 \Rightarrow j \in \rho\right\}$, otherwise $\tau_{i j}$ would not be defined. Further, from Proposition $j \in \tau^{i} \Rightarrow j \in \rho$. Now, suppose that there is a group $j^{\prime} \neq j$ that is only recognized by group $i$, but not anyone else in society. Since $\sigma \in \mathfrak{L}$, let $i$ choose not to make any transfer to $j$. In this case, $j^{\prime} \in \rho$, but $j^{\prime} \notin \tau$. Hence, $\tau \subseteq \rho$, which completes the proof.

Proof of Proposition 19 We demonstrate the proof for the case of a heterogeneous society ( 
homogeneous society is trivial since redistribution is irrelevant. The lifetime welfare of an infinitely-lived individual $i$ is given by

$$
W(\tau)=E_{t} \sum_{s=t}^{\infty} \delta_{i}^{s-t} W_{i, s}\left(\tau_{i j, s}\right),
$$

where $\delta_{i}$ is the discount factor of individual $i$. Without loss of generality, let the one-time shock occur at time $T$. Voluntary redistribution at time $t$ of $\tau_{i j, t}>0$ occurs if and only if

$$
W\left(\tau_{i j, t}>0, \tau_{j i, T}>0 ; \pi\right) \geq W(\tau=0)
$$

where $W\left(\tau_{i j, t}>0, \tau_{j i, T}>0 ; \pi\right) \equiv W_{i, t}\left(\tau_{i j, t}>0\right)+\sum_{s=t+1}^{T-1} \delta_{i}^{s} W_{i, s}\left(\tau_{i j, s}=0\right)+$ $\pi \delta_{i}^{T-t} W_{i, T}\left(\tau_{j i, T}>0\right)+(1-\pi) \delta_{i}^{T-t} W_{i, T}\left(\tau_{i j, T}=0\right)+\sum_{s=T+1}^{\infty} \delta_{i}^{s} W_{i, s}\left(\tau_{i j, s}=0\right)$. This condition is satisfied when

$$
W_{i, t}\left(\tau_{i j, t}>0\right)+\pi \delta_{i}^{T-t} W_{i, t}\left(\tau_{j i, t}>0\right) \geq\left(1+\pi \delta_{i}^{T-t}\right) W_{i, t}\left(\tau_{i j, t}=0\right) .
$$

Since $\frac{\partial W}{\partial \tau_{i j}} \leq 0$ and $\frac{\partial W}{\partial \tau_{j i}} \geq 0$, and assuming further that $W_{i, t}\left(\tau_{j i, t}>0\right)>$ $W_{i, t}\left(\tau_{i j, t}=0\right)>W_{i, t}\left(\tau_{i j, t}>0\right)$ (transfers received (given) yields higher (lower) welfare than no transfer), the condition will be satisfied if

$$
W_{i, t}\left(\tau_{i j, t}>0\right) \ll W_{i, t}\left(\tau_{j i, t}>0\right)
$$

for sufficiently high $\delta_{i}$ and $\pi$, which is the condition stated in the proposition.

Proof of Proposition 14 As in Proposition $1 \overline{3}$, we demonstrate the proof for the case of a heterogeneous society. The lifetime welfare of an infinitely-lived dictator $d$ is given by

$$
W(\tau)=E_{t} \sum_{s=t}^{\infty} \delta_{d}^{s-t} W_{d, s}\left(\tau_{d j, s}\right),
$$

where $\delta_{d}$ is the discount factor of the dictator. Without loss of generality, let the one-time shock occur at time $T$. By Proposition ${ }_{2}^{i} \tau_{d j} \geq 0 \Rightarrow j \in \rho^{d}=\rho$. Taxation, and voluntary recognition, at time $t$ of $\tau_{j d, t}>0$ occurs if and only if

$$
W\left(\tau_{j d, T}>0 ; \mu\right) \geq W(\tau=0)
$$

where $W\left(\tau_{j d, T}>0 ; \mu\right) \equiv \sum_{s=t}^{T-1} \delta_{d}^{s} W_{d, s}\left(\tau_{j d, s}=0\right)+\mu \delta_{d}^{T-t} W_{d, T}\left(\tau_{j d, T}>0\right)+$ $(1-\mu) \delta_{d}^{T-t} W_{d, T}\left(\tau_{j d, T}=0\right)+\sum_{s=T+1}^{\infty} \delta_{d}^{s} W_{d, s}\left(\tau_{j d, s}=0\right)$. This condition is satisfied whenever

$$
\mu \geq 0
$$

